\title{
Evaluation of biomass pretreatment to optimize process factors for different organic acids via Box-Behnken RSM method
}

\author{
Çağdaş Gönen ${ }^{1} \mathbb{D}$ Ece Ümmü Deveci ${ }^{1} \cdot$ Nagehan Akter Önal $^{1}$
}

Received: 16 September 2020 / Accepted: 12 July 2021 / Published online: 22 July 2021

๑) Springer Japan KK, part of Springer Nature 2021

\begin{abstract}
Biomass, as renewable energy source, is of importance to investigate to extend the conversion yield by microorganism. Because of lignocellulosic structure, biomass must be pretreated with a process, frequently inorganic acid has to be used with a problem of hazardous byproducts. Organic acid pretreatment is an efficient alternative to be investigated. Sugar beet pulp, as an agro-industrial residue of microorganism, can be utilized by pretreatment, which is usually a costly process. Pretreatment with organic acids creates a great opportunity to convert the process into more economic and effective. Moreover, pressure conditions significantly increase the yield of biodegradable sugar content. In this study, different organic acids of maleic, fumaric, oxalic, and acetic acid pretreatment was investigated to pretreatment of sugar beet pulp, which came vast amount from factories, under pressure and non-pressure conditions via Box-Behnken method to estimate optimum point of acid ratio $(1,3,5 \%)$, time $(10,27.5,45 \mathrm{~min})$, and solid ratio factors $(3,6.5,10 \%)$ for highest degradation. Results were also evaluated economically. As a result of the experiments, it was observed that acetic acid gave the best result with $409.16 \mathrm{~g} / \mathrm{L}$ total sugar concentration than the other organic acids. The highest TS concentration of maleic, oxalic, and fumaric acid were $97.26,97.85$, and $91.37 \mathrm{~g} / \mathrm{L}$, respectively, under pressure. According to economical evaluation, owing to lower market price and highest TS formation yield, pretreatment cost of acetic acid pretreatment was found averagely $1.51 \$ / \mathrm{gTS}$ under pressure conditions.
\end{abstract}

Keywords Biomass $\cdot$ Sugar cane pulp $\cdot$ Pretreatment $\cdot$ Organic acid $\cdot$ Box-Behnken

\section{Introduction}

Biomass is defined as plant, wood or animal residues that can burn directly or turn into fuel [1]. The structure of lignocellulosic raw materials is quite complex and resistant against to enzymatic hydrolysis. For this reason, pretreatments applied to the raw material are important before enzymatic hydrolysis. There are many pretreatment methods to separate cellulose hemicellulose and lignin components in lignocellulosic material [2]. The importance of pretreatments applied to lignocellulosic material has long been known. With various pretreatment methods, the size of the biomass is reduced, lignin and hemicellulose are separated

Çă̆daş Gönen

cagdas.gonen@ohu.edu.tr

1 Department of Environmental Engineering, Engineering Faculty, Niğde Ömer Halisdemir University Campus, 51240 Niğde, Turkey from the biomass, the crystallized structure of the cellulose is reduced and the biomass is porous [3].

There are some points to be considered during the pretreatments applied to biomass; avoiding the come out of byproducts that may have an inhibitory effect for microorganisms during fermentation and hydrolysis, minimizing the loss of carbohydrates and keeping the cost as low as possible while performing all these processes. The general purpose of the pretreatment technologies is to eliminate the substances that will interfere with the hydrolysis process, to provide fermented sugar formation from cellulose and hemicellulose and as a result increase the hydrolysis efficiency. The pretreatment stage is important to increase product efficiency and nearly $18 \%$ of the production cost come from this step [4].

The energy potential of biomass has been shown in previous studies. However, due to the heterogeneity and crystallinity properties of the lignocellulosic structure in the biomass, its direct use and degradability by microorganisms is extremely low. Therefore, there is a need for pretreatment 
to convert the biomass containing lignocellulosic structure into a structure that can be used by microorganisms. The literature studies on the pretreatment methods are given in Table 1.

In 2015, Asakawa et al. tried ionic liquid treatment as a pretreatment method in their research. They used sugarcane pulp as raw materials and choline acetate ([Cho] [OAc]) was used to increase lignocellulosic enzymatic saccharification. As different pretreatments: they compared the percentage of energy efficiency using alkali pretreatment, microwave, and physical comminution methods. They obtained the maximum yield percentage of $0.35 \mathrm{~g}$ glucose $\left(360 \mathrm{~min}\right.$ at $\left.110^{\circ} \mathrm{C}\right)$ per $1 \mathrm{~g}$ of raw pulp. By pretreatment, pulp cellulose content was converted to $98.7 \%$ glucose [5].

In the study of Sami Luste and Sari Luostarinen, they used dairy cattle fertilizer as raw materials and investigated the effect of heat treatment and ultrasonic sound application on the methane yield. While biological methane potential (BMP) was $210 \mathrm{Nm}^{3} \mathrm{CH}_{4}$ /ton (UACM) before ultrasonic sound pretreatment, they determined $250 \pm 10 \mathrm{Nm}^{3} \mathrm{CH}_{4} /$ ton (UACM) after ultrasonic sound pretreatment. After heat treatment, it reached $280 \mathrm{Nm}^{3} \mathrm{CH}_{4} /$ ton (UACM) [6].

Michalsk and Ledakowicz investigated the effect of alkali pretreatment on the anaerobic decomposition of lignocellulosic raw material and used two important plant species Miscanthus giganteus and Sida hermaphrodita as raw materials for energy production in their study. They applied alkaline pretreatment with $\mathrm{NaOH}$ and compared the methane and biogas yields before and after pretreatment. The best results were about $64 \%$ biogas yield for M. Giganteus [7].

The most preferred method in previous studies in the literature is pretreatment with dilute sulfuric acid at high temperatures [8-10]. However, in pretreatments with sulfuric acid, it is seen that hemicellulose and cellulose decompose into molecules such as furfural. Compounds formed as a result of pretreatments with inorganic acids can inhibit fermentation and cause sugar losses [11-13]. For these reasons, it has been inevitable to research different pretreatment methods recently. It has been seen in recent studies that organic acids are more advantageous than inorganic acids.
For example, Kootstra et al. examined the activities of fumaric, maleic, and sulfuric acid on wheat straw, and it was stated that organic acids may be an alternative to mineral acids [14, 15]. In addition, pretreatment with organic acids has been tested on some lignocellulosic materials such as maple, hardwoods, mixed hardwoods, and corn waste, and it has been stated that organic acids are an effective pretreatment to break down the lignocellulosic structure [16-19]. Organic acids are less corrosive than sulfuric acid, which is an important advantage. In addition, it has been reported to reduce the amount of pretreatment sugar degradation products with organic acids [19]. Based on this information, different organic acids (maleic, oxalic) and various pretreatments were applied to the sugar beet pulp determined as raw material in this study.

The factors of this study chosen according to the literature values. In Table 2, different temperatures are set for the pretreatment studies with organic acid or dilute acid, the range of temperature can change from 30 to $200{ }^{\circ} \mathrm{C}$. It is clear that the temperature factor is significant for the biomass pretreatment. On the other hand, reaction time is another important parameter for biomass pretreatment. Sufficient time is needed to complete the chemical reaction. From Table 2, in common, reaction time changes from 5 to $120 \mathrm{~min}$ for biomass pretreatment. To degrade the chemical

Table 2 Reaction time, temperature, and acid ratio of some various literature studies for on pretreatment methods

\begin{tabular}{llll}
\hline Temperature $\left({ }^{\circ} \mathrm{C}\right)$ & Time (minute) & Acid ratio & Reference \\
\hline $120-140$ & $20-60$ & $0.5-1.5 \%$ & {$[24]$} \\
$30-90$ & $30-60$ & $2-12 \%$ & {$[28]$} \\
$100-140$ & $30-60$ & $5-15 \%$ & {$[29]$} \\
100 & $17.6-102.4$ & $0.35-10 \%$ & {$[30]$} \\
$70-100$ & $60-120$ & $15 \%$ & {$[31]$} \\
$160-200$ & $5-15$ & $1-3 \%$ & {$[32]$} \\
120 & $15-120$ & $0.5-5 \%$ & {$[33]$} \\
$130-190$ & 30 & $50-90 \mathrm{mmol} / \mathrm{L}$ & {$[20]$} \\
$130-150$ & $60-120$ & $10-200 \mathrm{mmol} / \mathrm{L}$ & {$[34]$} \\
\hline
\end{tabular}

Table 1 Various literature studies on pretreatment methods

\begin{tabular}{lllll}
\hline Pretreatment method & Biomass & Degradation & Biogas efficiency & Reference \\
\hline Mechanical pretreatment & Algae & - & $+\% 52$ & {$[3]$} \\
& Laminaria spp. & & & \\
Ultrasound & Dairy cattle manure and glycerol & - & $+\% 19$ & {$[28]$} \\
Thermal process & Dairy cattle manure & - & $+\% 34$ & {$[28]$} \\
Ionic liquid & Untreated wood residue & $\% 90$ & $+\% 78$ & {$[29]$} \\
Ionic liquid & Sugarcane pose & $\% 98.7$ & & {$[5]$} \\
Alkali pretreatment & Macroalgae & - & $+\% 64$ & {$[7]$} \\
Alkali pretreatment & Rice & $\% 66.8$ & $564 \mathrm{ml} / \mathrm{g} \mathrm{UKM}$ & {$[30]$} \\
Enzymatic hydrolyze & Ulva rigida & - & $\% 62.65$ & {$[31]$} \\
\hline
\end{tabular}


bonds of cellulosic and lignocellulosic components in biomass, reactant of acid concentration is of significant. Acid ratios depend on the acid type and can be changed from 0.3 to $15 \%$. Proper time, temperature, and reactant concentration means recovering more hydrocarbon structure from the biomass. Table 2 shows reaction time, temperature, and acid ratio of some studies related to biomass pretreatment. Dilute oxalic acid pretreatment was studied by Qing et al., according to study, while reaction temperature was between 120 and $140{ }^{\circ} \mathrm{C}$ and reaction time were $20-60 \mathrm{~min}$, dilute acid ratio was $0.5-1.5 \%$ [24]. Sahu and Pramanik worked with organic acid pretreatment and they preferred experimental design factors as $30-90{ }^{\circ} \mathrm{C}, 30-60 \mathrm{~min}$, and $2-12 \%$ [28]. Another study related to biomass pretreatment for succinic production, the experimental factors were determined as $100-140{ }^{\circ} \mathrm{C}, 30-60$ min reaction time, and $5-15 \%$ acid ratio [29]. Rattanaporn et al. reported that experimental factors were set $100{ }^{\circ} \mathrm{C}, 17.6-102.4 \mathrm{~min}$, and $0.35-10 \%$ acid ratio to pretreatment of oil palm [30]. In another study by Oktaviani et al., tropical lignocellulose biomass pretreatment was studied using maleic acid and experimental conditions were determined as $70-100{ }^{\circ} \mathrm{C}, 60-120 \mathrm{~min}$, and $15 \%$ maleic acid ratio [31]. Optimization of organic acid pretreatment of wheat straw was investigated by Barisik et al. and factors of temperature, reaction time, and acid ratio were $160-200{ }^{\circ} \mathrm{C}$, 5-15 min, and 1-3\%, respectively [32]. Another report indicates the experiential factors as $120^{\circ} \mathrm{C}, 15-120 \mathrm{~min}$, and $0.5-5 \%$ acid ratio to pretreatment of rice straw by organic acids [33].

It is understood from the studies in the literature that the temperature and pressure parameters are important parameters especially in organic acid pretreatment. The efficiency of the pretreatment process is directly affected by the temperature and pressure parameters. Because, it is known that the efficiency of a chemical reaction is directly proportional to the unit surface area size of the reactant. It can be said that temperature is an effective parameter in the pretreatment process since the temperature factor will change the reaction equilibrium and increase the chemical reaction threshold energy. In addition, the pressure also increases the solubility like temperature [20-24]. In this study, pretreatment process with organic acids was preferred. Although they do not show pretreatment efficiency as much as mineral acids, considering the operating conditions, production methods and costs, it is known that organic acids are used in pretreatment processes. It is also known that intermediates formed in mineral acid pretreatment could inhibit biodegradability $[11,13,23,25]$.

In this study, sugar beet pulp was used as biomass source to investigate the effect of the different organic acid, which are maleic acid, fumaric acid, oxalic acid, and acetic acid, pretreatment under pressure and non-pressure conditions to produce consumable sugar formation. Because microorganism cannot directly and efficiently use the biomass source if it is containing lignocellulosic structure. That's why lignocellulosic and cellulosic structure has to be decomposed to smaller sugar formation which is defined as total sugar or reduced sugar. Box-Behnken response surface methodology design was used to optimize the factors, which are acid concentration, reaction time, and solid ratio of raw material to calculate maximum TS and RS formation value. Sugar beet pulp was preferred as raw material because vast amount of sugar beet pulp was come with too low price from factories as agro-industrial waste. It is of importance to study these agro-industrial biomass waste come from factories.

\section{Materials and methods}

\section{Raw material and preparation}

Sugar cane pulp were supplied from local sugar factory in Niğde City of Turkey. Raw material was washed with tap water and then was dried at $60^{\circ} \mathrm{C}$ for $48 \mathrm{~h}$. Dried sugar cane pulp was grinded by IKA MF10 and then sieved and separate different dimensions by screening. Finally, all prepared materials stored at $+4{ }^{\circ} \mathrm{C}$ during all experiments.

\section{Pretreatment method}

To optimize the application of acidic pretreatment to the lignocellulosic raw material, the acid concentration, processing time, and solid ratio parameters were tried to be optimized. Maleic acid, oxalic acid, acetic acid, and fumaric acid (all chemicals from Sigma-Aldrich) solutions were prepared to create the targeted acidic environment. Pretreatment experiments were carried out in $100 \mathrm{ml}$ volume flasks under pressure and non-pressure conditions. Reaction temperature was set at $100{ }^{\circ} \mathrm{C}$ at non-pressure conditions and $121{ }^{\circ} \mathrm{C}$ at $1.2 \mathrm{~atm}$ under pressure conditions. After the pretreatment process, which are under controlled acidic conditions and different temperatures, samples were filtered to solid liquid separation and then liquid phase was centrifuged at $10,000 \mathrm{rpm}$ for $10 \mathrm{~min}$. Finally, samples $\mathrm{pH}$ was set to between 6-8 to make total sugar and reduced sugar concentration analysis. $6 \mathrm{M} \mathrm{NaOH}$ solution was prepared to make $\mathrm{pH}$ neutralization.

\section{Analysis}

In the samples prepared for the analysis, total sugar analysis and reducing sugar analysis were performed. Dinitrosalicylic acid method was used for reducing sugar analysis [26]. Total sugar determination was done by phenol-sulfuric acid calorimetric method [27]. 


\section{Experimental design of response surface method}

All pretreatment test patterns in this study were designed with the Box-Behnken method and the results were statistically evaluated by the surface response method. Experimental designs and estimation the coefficients of the model were prepared with Design Expert software. Under pressure and non-pressure conditions, all experiments were done with the factor of time, solid ratio, and acid ratio. The high and low level of time factor is $5-45 \mathrm{~min}$, solid ratio factor is $3-10 \%$ and of acid ratio factor is $1-5 \%$. In experiments carried out in a non-pressure environment, the temperature was kept constant at $100{ }^{\circ} \mathrm{C}$. Under pressure conditions, temperature was $121^{\circ} \mathrm{C}$ and pressure was set $1.2 \mathrm{~atm}$ for experiments.

All pretreatment experiments patterns are designed with the Box-Behnken statistical method and the results are statistically evaluated by the surface response method. The experimental design prepared with the Box-Behnken method is given in Table 3. For all organic acids same acid concentration was used.

\section{Economic evaluation}

The economic evaluation of TS production by the optimum conditions of studied factors was determined for different organic acids and both with and without pressure conditions was calculated. Equation 1 was used to calculate unit cost of gram TS formation from sugar beet pulp.

Table 3 Factors and levels for all experiment from Box-Behnken method

\begin{tabular}{llll}
\hline Experiment no & $\begin{array}{l}\text { Acid ratio } \\
(\%)\end{array}$ & Time (minute) & Solid ratio (\%) \\
\hline 1 & 1 & 45 & 6.5 \\
2 & 1 & 27.5 & 10 \\
3 & 3 & 10 & 3 \\
4 & 3 & 10 & 10 \\
5 & 5 & 45 & 6.5 \\
6 & 1 & 10 & 6.5 \\
7 & 1 & 27.5 & 3 \\
8 & 3 & 27.5 & 6.5 \\
9 & 5 & 27.5 & 10 \\
10 & 5 & 10 & 6.5 \\
11 & 3 & 45 & 3 \\
12 & 5 & 27.5 & 3 \\
13 & 3 & 27.5 & 6.5 \\
14 & 3 & 27.5 & 6.5 \\
15 & 3 & 45 & 10 \\
16 & 3 & 27.5 & 6.5 \\
17 & 3 & 27.5 & 6.5 \\
\hline
\end{tabular}

Euation for Cost : Unit Cost $\left(\frac{\$}{g \mathrm{TS} . L}\right)$

$$
=\frac{\operatorname{Acid} \operatorname{Price}\left(\frac{\Phi}{X}\right) x \text { Amoutn of acid per hour }\left(\frac{X}{h}\right)}{\text { TS concentratin }\left(\frac{g}{L}\right) / \operatorname{Reaction} \operatorname{time}(h)} \text {. }
$$

\section{Result and discussion}

Pretreatment studies were carried out with maleic acid, fumaric acid, oxalic acid, and acetic acid under pressure (1.2 atm) and non-pressure (1 atm) conditions with 3 different factor of acid ratio, reaction time, and solid ratio which are independent variables for the optimization study of sugar beet pulp pretreatment. Total sugar responses of all experiments under different pressure conditions, according to the Box-Behnken experimental design, are given at Table 4.

According to the response surface methodology, there are so many 3 axis graphs were drowned for TS results. Although effect of the factors is explained, graphs are not given at the manuscript. They can be found as supplementary file.

\section{Total sugar formation responses for all organic acids}

Pretreatment with maleic acid, when the solid ratio and maleic acid concentration factors are at maximum level of 10 and 5\%, the TS concentration could be rise up to maximum level. TS, in $27.5 \mathrm{~min}$ and $10 \%$ maleic acid concentration, can be increased up to $7.5 \mathrm{~g} / \mathrm{L}$ under non-pressure conditions. On the other hand, under pressure conditions with maleic acid pretreatment, the TS concentration in $27.5 \mathrm{~min}$ and $3 \%$ acid concentration was increase up to $9 \mathrm{~g} / \mathrm{L}$. When the maleic acid percentage and solid ratio were increased, the TS concentration could be up to $8.9 \mathrm{~g} / \mathrm{L}$. However, the increase in acid concentration alone did not cause a significant increase in TS concentration. Kootstra et al. reported that maleic acid is more effective than fumaric acid in their study where the raw material is wheat straw and indicated that it is an important alternative to hydrolysis of strong acids such as sulfuric acid. To be an alternative to strong acids, hydrolysis should be done at high temperatures such as $150{ }^{\circ} \mathrm{C}$ [15]. Another study indicates that dilute fumaric or maleic acid are more effective than the sulfuric acid. If solid ratio reaches up to $30 \%$, acid pretreatment performance would be similar with enzymatic pretreatment, however, furfural formation will be begun, which should be considered carefully [14]. Promising pretreatment agent of maleic acid can be result to $88 \%$ of delignification with biomass of 


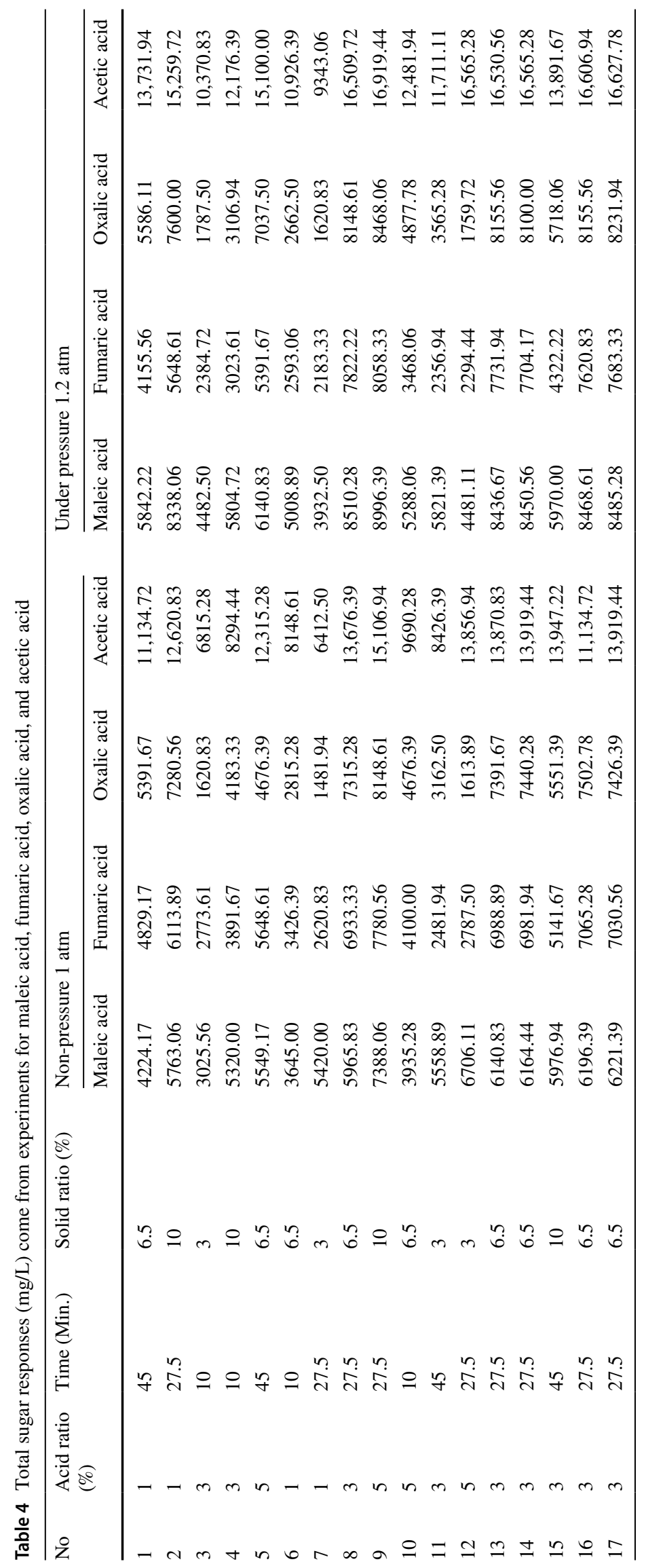


cotton in $45 \mathrm{~min}$ and $140{ }^{\circ} \mathrm{C}$ under non-pressure conditions [28].

Pretreatment with oxalic acid, effect of factors was examined under both under and non-pressure conditions. When the levels of reaction time and oxalic acid concentration factors were increased to their highest level, the TS concentration was up to $8 \mathrm{~g} / \mathrm{L}$ under non-pressure conditions. In parallel, the acid and solid ratio factors were increased, the TS concentration rise up to $8.1 \mathrm{~g} / \mathrm{L}$. It could be said that the increase in acid concentration does not have a significant effect alone. But acid ratio factor interaction with other factors can be affect the response of the TS concentration in positive way. In contrary under pressure conditions of $1.2 \mathrm{~atm}$, oxalic acid pretreatment of sugar cane pulp, the TS response increased up to $8.5 \mathrm{~g} / \mathrm{L}$ in rising the levels of the time and oxalic acid concentration factors to $45 \mathrm{~min}$ and $5 \%$. Moreover, when the solid ratio and acid concentrations were increased, the TS concentration could reach up to $8.8 \mathrm{~g} / \mathrm{L}$. The changing in oxalic acid concentration between highest and lowest value of 1-5\% does not have a significant effect alone on the TS responses. When the solid ratio and time factors were increased to their highest level of $10 \%$ and $45 \mathrm{~min}$, the TS concentration was rise up to $8.8 \mathrm{~g} / \mathrm{L}$. Bukhari et al. studied oil palm trunk as lignocellulosic material in dissolved sugar production. Formic acid, citric acid, and oxalic acid were used as organic acids for the pretreatment of the oil palm trunk. According to the results obtained experiments, the lowest amount of dissolved sugar $(<0.5 \mathrm{~g} / \mathrm{L})$ was determined in citric acid, and the amount of dissolved sugar (Glucose and Xylose) released by pretreatment with oxalic acid and formic acid was higher than citric acid [29].

Rattanaporn et al. (2018) were reported that oxalic acid $\left(\mathrm{C}_{2} \mathrm{H}_{2} \mathrm{O}_{4}\right)$, acetic acid $\left(\mathrm{C}_{2} \mathrm{H}_{4} \mathrm{O}_{2}\right)$, citric acid $\left(\mathrm{C}_{6} \mathrm{H}_{8} \mathrm{O}_{7}\right)$, hydrochloric acid $(\mathrm{HCl})$, sodium citrate, and sodium azide were used for biomass pretreatment and experiments were designed based on RSM with Box-Behnken method. While the dissolved sugar content in the environment without pretreatment was $0.7804 \mathrm{mg} / \mathrm{ml}$, it was determined as $1.7975 \mathrm{mg} / \mathrm{ml}$ as a result of oxalic acid pretreatment and has the highest sugar content compared to citric acid and acetic acid [30]

TS responses can be reach up to $7.7 \mathrm{~g} / \mathrm{L}$ at the fumaric acid pretreatment experiment under non-pressure conditions. It can be observed that the fumaric acid concentration not significantly supported the degradation but interaction with either time or solid ratio factor significantly increase de degradation of sugar pulp and final product concentration of TS can be rise nearly $8.0 \mathrm{~g} / \mathrm{L}$ at $27.5 \mathrm{~min}$ of time factor and almost $10 \%$ of solid ratio of sugar cane pulp. When both solid ratio and time factor were investigated, highest level of solid ratio factor $(10 \%)$ and center point of time factor $(27.5 \mathrm{~min})$ gave the maximum TS responses at fumaric acid pretreatment under non-pressure conditions. Regarding under pressure conditions with fumaric acid pretreatment, TS concentration can be rise over $8.0 \mathrm{~g} / \mathrm{L}$. Although changing the value of acid ratio factor cannot be strongly affected the TS response, changing time or solid ratio factor significantly affected the TS formation from sugar beet pulp. Center point level of time (27.5 $\mathrm{min})$ and solid ratio $(6.5 \%)$ factor were given highest response of $8.0 \mathrm{~g} / \mathrm{L}$ TS.

Another organic acid pretreatment experiment was done by acetic acid. The highest TS concentration value was $15.8 \mathrm{~g} / \mathrm{L}$ under non-pressure conditions with acetic acid pretreatment. It was clearly observed that acetic acid factor was significantly affected the TS concentration and highest acetic acid ratio caused highest TS concentration. Although time factor significantly affected the TS formation, different from the acid ratio factor, at center point of time factor which is 27.5 min gave highest TS concentration. Relationship between solid ratio factor and TS result are linearly dependent and highest TS concentration of $15.8 \mathrm{~g} / \mathrm{L}$ was observed at maximum level of solid ratio $(10 \%)$ under nonpressure conditions. TS result at under pressure conditions with acetic acid pretreatment can be over $17.7 \mathrm{~g} / \mathrm{L}$. While acetic acid and solid ratio factor significantly and linearly affected the TS concentration, time factor affected the TS concentration on 2 nd order function and center point of time factor (27.5 $\mathrm{min})$ gave the highest response of TS concentration $(15.8 \mathrm{~g} / \mathrm{L})$. In a study by Lee et al., Box-Behnken design was preferred to optimize hydrothermal pretreatment with corn stover acetic acid. According to the results obtained that the optimum total sugar concentration was determined $20.08 \mathrm{~g} / \mathrm{L}$ at $0.25 \%$ acetic acid concentration and $191{ }^{\circ} \mathrm{C}$.

To find optimum point of factors to gain maximum TS concentration, Box-Behnken response surface experimental method was used with the factors of acid ratio, reaction time, and solid ratio (as raw material) for maleic acid, fumaric acid, oxalic acid, and acetic acid pretreatment of sugar beet pulp degradation. 17 experiments were done for each different pretreatment according to the Box-Behnken statistical design experimental pattern. Result model functions were evaluated by experimental TS results. Table 5 shows response model function and $\mathrm{R}^{2}$ values for each different pretreatment and also it indicates that optimum factor points for the highest TS results. The highest TS result derivate by software for optimum point of factors. It is clearly said that under pressure conditions give much better TS result than the non-pressure conditions. While the highest TS concentration can be rise up to $10 \%$ with fumaric acid and acetic acid pretreatment at optimum factors conditions at under pressure conditions, it can be increase up to $20 \%$ and $8 \%$ by maleic acid and oxalic acid pretreatment. It is obviously observed that acetic acid pretreatment gave highest TS concentration of $17 \mathrm{~g} / \mathrm{L}$. Optimum point of reaction time factor is almost similar with $30 \mathrm{~min}$ for all different pretreatment 
Table 5 Model functions, constants, and optimum points of factors for maximum TS concentration for fumaric, oxalic, maleic, and acetic acid experiments

\begin{tabular}{|c|c|c|c|c|c|c|}
\hline Pretreatment & Acid ratio $(\%)$ & Time (Min.) & Solid ratio $(\%)$ & $\begin{array}{l}\text { TS result } \\
(\mathrm{mg} / \mathrm{L})\end{array}$ & Response function & $R^{2}$ \\
\hline \multicolumn{7}{|l|}{$\begin{array}{l}\text { Non-pressure } \\
1 \mathrm{~atm}\end{array}$} \\
\hline Maleic acid & 4.99 & 31.47 & 9.98 & 7452.81 & $\begin{aligned}= & +6137.78+565.80 \times \mathrm{A}+672.92 \times \mathrm{B}+467.19 \times \mathrm{C}+258.6 \\
& 8 \times \mathrm{A} \times \mathrm{B}+84.72 \times \mathrm{A} \times \mathrm{C}-469.10 \times \mathrm{B} \times \mathrm{C}-225.21 \times \mathrm{A}^{2}- \\
& 1574.17 \times \mathrm{B}^{2}+406.74 \times \mathrm{C}^{2}\end{aligned}$ & 0.95 \\
\hline Fumaric acid & 4.03 & 30.92 & 8.53 & 7599.38 & $\begin{aligned}= & +7000.00+415.80 \times \mathrm{A}+488.72 \times \mathrm{B}+1532.99 \times \mathrm{C}+36.46 \\
& \times \mathrm{A} \times \mathrm{B}+375.00 \times \mathrm{A} \times \mathrm{C}+385.42 \times \mathrm{B} \times \mathrm{C}-622.74 \times \mathrm{A}^{2}- \\
& 1876.22 \times \mathrm{B}^{2}-1551.56 \times \mathrm{C}^{2}\end{aligned}$ & 0.91 \\
\hline Oxalic acid & 3.29 & 29.97 & 8.66 & 8147.5 & $\begin{aligned}= & +7415.28+268.23 \times \mathrm{A}+685.76 \times \mathrm{B}+2160.59 \times \mathrm{C} \\
& -644.10 \times \mathrm{A} \times \mathrm{B}+184.03 \times \mathrm{A} \times \mathrm{C}-43.40 \times \mathrm{B} \times \mathrm{C}- \\
& 1011.81 \times \mathrm{A}^{2}-2013.54 \times \mathrm{B}^{2}-1772.22 \times \mathrm{C}^{2}\end{aligned}$ & 0.92 \\
\hline Acetic acid & 4.92 & 29.09 & 6.65 & $15,643.9$ & $\begin{array}{l}=+13,304.17+2482.64 \times \mathrm{A}+1815.97 \times \mathrm{B}+1750.00 \\
\times \mathrm{C}-90.28 \times \mathrm{A} \times \mathrm{B}-1239.58 \times \mathrm{A} \times \mathrm{C}+1010.42 \times \mathrm{B} \times \mathrm{C}-1 \\
76.74 \times \mathrm{A}^{2}-2805.21 \times \mathrm{B}^{2}-1128.13 \times \mathrm{C}^{2}-413.19 \times \mathrm{A}^{2} \times \\
\mathrm{B}+114.58 \times \mathrm{A}^{2} \times \mathrm{C}-1802.08 \times \mathrm{A}^{2} \mathrm{~B}^{2}\end{array}$ & 0.96 \\
\hline \multicolumn{7}{|l|}{$\begin{array}{l}\text { Pressure } \\
1.2 \mathrm{~atm}\end{array}$} \\
\hline Maleic acid & 3.24 & 28.49 & 8.66 & 8895.9 & $\begin{aligned}= & +8470.28+223.09 \times \mathrm{A}+398.78 \times \mathrm{B}+1298.96 \times \mathrm{C}+4.86 \\
& \times \mathrm{A} \times \mathrm{B}+27.43 \times \mathrm{A} \times \mathrm{C}-293.40 \times \mathrm{B} \times \mathrm{C}-991.46 \times \mathrm{A}^{2}- \\
& 1908.82 \times \mathrm{B}^{2}-1041.81 \times \mathrm{C}^{2}\end{aligned}$ & 0.96 \\
\hline Fumaric acid & 3.86 & 30.83 & 8.19 & 8166.26 & $\begin{aligned}= & +7712.50+578.99 \times \mathrm{A}+594.62 \times \mathrm{B}+1479.17 \times \mathrm{C}+90.28 \\
& \times \mathrm{A} \times \mathrm{B}+574.65 \times \mathrm{A} \times \mathrm{C}+331.60 \times \mathrm{B} \times \mathrm{C}-1143.06 \times \mathrm{A}^{2}- \\
& 2667.36 \times \mathrm{B}^{2}-2023.26 \times \mathrm{C}^{2}\end{aligned}$ & 0.93 \\
\hline Oxalic acid & 3.44 & 33.74 & 8.42 & 8818.01 & $\begin{aligned}= & +8158.33+584.20 \times \mathrm{A}+1184.03 \times \mathrm{B}+2019.97 \times \mathrm{C} \\
& -190.97 \times \mathrm{A} \times \mathrm{B}+182.29 \times \mathrm{A} \times \mathrm{C}+208.33 \times \mathrm{B} \times \mathrm{C}- \\
& 899.83 \times \mathrm{A}^{2}-2217.53 \times \mathrm{B}^{2}-2396.35 \times \mathrm{C}^{2}\end{aligned}$ & 0.92 \\
\hline Acetic acid & 4.82 & 30.47 & 5.82 & $17,507.8$ & $\begin{array}{l}+16,568.06+1475.69 \times \mathrm{A}+1059.90 \times \mathrm{B}+1282.12 \\
\times \mathrm{C}-46.87 \times \mathrm{A} \times \mathrm{B}-1390.63 \times \mathrm{A} \times \mathrm{C}+93.75 \times \mathrm{B} \times \mathrm{C}- \\
511.81 \times \mathrm{A} 2-2996.18 \times \mathrm{B} 2-1534.37 \times \mathrm{C} 2\end{array}$ & 0.94 \\
\hline
\end{tabular}

$\mathrm{A}$ is acid ratio; $\mathrm{B}$ is time, and $\mathrm{C}$ is solid ratio for the response function

for highest TS result. Even the highest concentration could be achieved by acetic acid pretreatment under pressure conditions, economical evaluation should be done to determine most economic process according to all factors impacts, because cost of acids and little differences of reaction time can be significantly affected the unit price of TS formation.

\section{Reduced sugar formation responses for all organic acids}

Table 6 shows responses of the reduced sugar for experiments. Reduced sugar is the one of significant indicate that when the lignocellulosic structure will break down via some pretreatment process, plus reduced sugar formation can be easily used by the microorganism to produce some energy compound such as biogas or bioethanol. In this study, reduced sugar was a response of the pretreatment process experiment for different organic acids under different pressure conditions. According to the reduced sugar responses from Box-Behnken experiments under non-pressure conditions with maleic acid pretreatment of sugar cane pulp, when the time and maleic acid concentration factor values were increased to $45 \mathrm{~min}$ and 5\%, the reducing sugar concentration could be reach up to $70 \mathrm{mg} / \mathrm{L}$. Similarly, when the solid ratio and the maleic acid dose were increased to their highest level, the reducing sugar concentration increased up to $82 \mathrm{mg} / \mathrm{L}$. The highest reducing sugar concentration was obtained when the solid content was $10 \%$ and the acid dose was $3 \%$ with maleic acid pretreatment. The RS result observed from maleic acid pretreatment experiments under pressure conditions, when the maleic acid concentration rises to $5 \%$ and time was increased to $45 \mathrm{~min}$, RS concentration could be up to $96 \mathrm{mg} / \mathrm{L}$. In similar RS concentration can reach up to $96 \mathrm{mg} / \mathrm{L}$ with the solid ratio of $10 \%$ and maleic acid concentration of 5\%. But it could be clear according to statistical model, maleic acid concentration did not cause any significant increase on reducing sugar concentration alone.

Oktaviani et al. [31] studied with sugarcane trash, corn cob, and sweet sorghum bagasse by pretreatment of maleic 


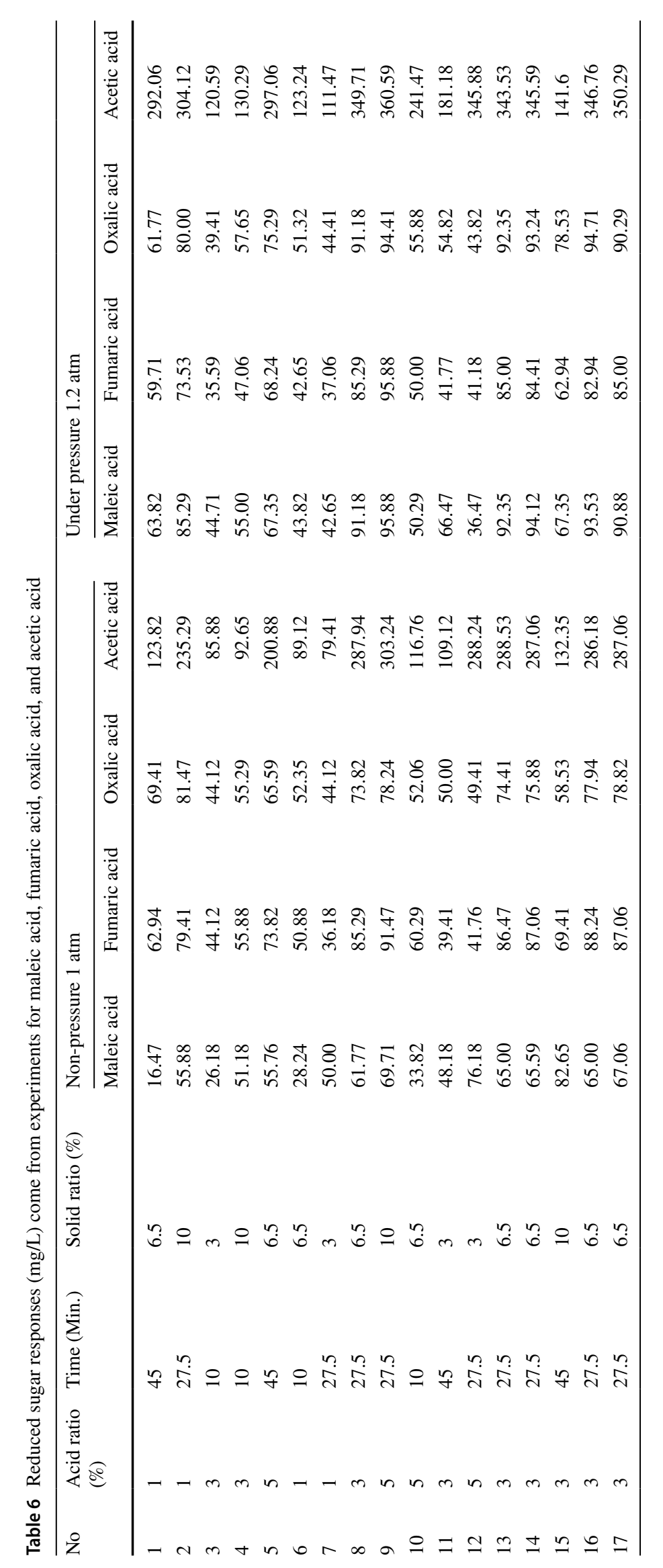


acid. They indicate that the highest xylose concentration $(14.2 \mathrm{~g} / \mathrm{L})$ was produced after treated by $2.5 \%$ of maleic acid at $121{ }^{\circ} \mathrm{C}$ for $60 \mathrm{~min}$ by corn cob and the highest glucose concentration $(24.7 \mathrm{~g} / \mathrm{L})$ was produced after treated by $3 \%$ of maleic acid $121{ }^{\circ} \mathrm{C}$ for $60 \mathrm{~min}$ by sweet sorghum bagasse [31]. Barisik et al. investigated the effects of different organic acids (maleic, succinic, and oxalic acid) on enzymatic hydrolysis and fermentation yields of wheat straw. According to the data reported, it was determined that succinic acid was not very efficient compared to maleic acid pretreatment. The ethanol yields obtained under optimum conditions were 80,79 , and $59 \%$ for maleic, oxalic, and succinic acid, respectively. These results show that the dissolved usable sugar content may be similar to this order [32].

The experiments of oxalic acid pretreatment were performed according to the Box-Behnken statistical experimental design, the reducing sugar concentration can rise up to $78 \mathrm{mg} / \mathrm{L}$ when the oxalic acid concentration and time factors are increased to $5 \%$ and $45 \mathrm{~min}$, similarly when the solid ratio and acid concentration increased to their highest level, the reducing sugar concentration increased up to $83 \mathrm{mg} / \mathrm{L}$. However, it is clear that the independent factor of oxalic acid concentration cannot be significantly affected the response of the reduced sugar concentration (graphics given as supplementary document). Reduced sugar responses according to oxalic acid pretreatment experiments under pressure conditions; when the oxalic acid concentration and time factor values are increased, the reducing sugar concentration can reach up to $95 \mathrm{mg} / \mathrm{L}$. When the solids ratio and acid concentration levels were increased, it was seen that reduced sugar concentration rise up to $96 \mathrm{mg} / \mathrm{L}$. In parallel non-pressure conditions, the increase in oxalic acid concentration alone did not have a significant effect on concentration.

Amnuaycheema et al. studied enzymatic hydrolysis and biogas production for reduced sugar from rice straw by pretreatment with oxalic acid via RSM. According to the results obtained, the optimum reduced sugar concentration at $5.01 \%$ oxalic acid at $135.91{ }^{\circ} \mathrm{C}$ for $30.86 \mathrm{~min}$ conditions was $213.4 \mathrm{mg} / \mathrm{L}$. When the biomass solid rate was controlled after pretreatment, the highest solid loss was in oxalic acid pretreatment [33]. Another study was done by Qing et al. that dilute sulfuric acid and dilute oxalic acid pretreatment were compared for corncob in terms of reducing sugar. After $96 \mathrm{~h}$ of pretreatment, the yield of sulfuric acid was $82.3 \%$, while the yield of oxalic acid was $90.3 \%$. The oxalic acid pretreatment method developed in this study was determined to be a suitable catalytic for high xylose recovery in pretreatment and high sugar recovery in subsequent enzymatic hydrolysis. In an experimental study by Quin et al. with corn stover, five different acids were used for pretreatment, including sulfuric acid, acetic acid, oxalic acid, tartaric acid, and citric acid. It has been determined that organic acids are more suitable for fermentable sugar production [24]. In the study conducted by Silva et al., the chemical and structural properties of sugar cane as a result of the catalysis of sugar cane by citric acid and sodium hydroxide were investigated and investigated on the enzymatic hydrolysis process [34]

RS concentration can be rise up to $92.60 \mathrm{mg} / \mathrm{L}$ with fumaric acid pretreatment experiments at $1 \mathrm{~atm}$ conditions. Like TS results, fumaric acid concentration differences were slightly affected the RS concentration. On the other hand, time and solid ratio factor significantly support the RS formation from sugar beet pulp. When the solid ratio was almost $8.25 \%$, time was $36.25 \mathrm{~min}$ and fumaric acid ratio was nearly $4 \%$, RS concentration can be at maximum level of $92.60 \mathrm{mg} / \mathrm{L}$ under non-pressure conditions. Under pressure conditions RS concentration can be rise up to $91.37 \mathrm{mg} / \mathrm{L}$. While time and solid ratio factors are more significantly affected the RS concentration, fumaric acid concentration is slightly changed the RS concentration. At $27.5 \mathrm{~min}$, which is optimum point of the time factor for maximum response value, TS concentration can be rise up to $91.37 \mathrm{mg} / \mathrm{L}$. On the other hand, when solid ratio factor was highest level of $10 \%$, RS concentration at highest level.

RS responses from acetic acid pretreatment under both non-pressure and pressure conditions were obtained from sugar bead pulp degradation experiments. RS responses can reach up to $320 \mathrm{mg} / \mathrm{L}$ under non-pressure conditions. While time factor was affected 2 nd order function and center point of time factor (27.5 min) caused to highest level of RS result, both factors of acetic acid ratio and solid ratio were linearly affected RS concentration in positive way. Highest level of solid ratio and acetic acid ratio, which are $10 \%$ and 5\%, respectively, gave $320 \mathrm{mg} / \mathrm{L}$ RS concentration under nonpressure conditions. RS concentration can be rise almost $420 \mathrm{mg} / \mathrm{L}$ under pressure condition with acetic acid pretreatment. Time and solid ratio factors can give maximum RS concentration at their center point level of $27.5 \mathrm{~min}$ and 6.5, respectively, moreover, both factors have 2 nd order function curve. Acetic acid concentration differences significantly affect the RS concentration in positive way and at highest level of factor gave highest level of RS response.

Gong et al. used acetic acid and propionic acid pretreatment for enzymatic hydrolysis of rice straw in their study. In the experimental solution, the medium has become acidic due to acetic acid. This has led to the obvious swelling of cellulose, increased inner surface area and deterioration of the crystalline structure. Then the structural chain between lignin and main structures was broken. Thus, lignin was dissolved in acetic acid solution. In the experiment where acetic acid and propionic acid were used together, the sugar yield was $35.28 \%$, while the sugar yield increased to $80.08 \%$ when the medium was supported by microwave [35]. Vanegas et al. reported that $6 \%$ acetic acid concentration give the 
Table 7 Model functions, constants, and optimum points of factors for maximum RS concentration for fumaric, oxalic, maleic, and acetic acid experiments

\begin{tabular}{|c|c|c|c|c|c|c|}
\hline $\begin{array}{l}\text { Pretreat- } \\
\text { ment }\end{array}$ & $\begin{array}{l}\text { Acid } \\
\text { ratio } \\
(\%)\end{array}$ & $\begin{array}{l}\text { Time } \\
\text { (Min.) }\end{array}$ & $\begin{array}{l}\text { Solid } \\
\text { ratio } \\
(\%)\end{array}$ & $\begin{array}{l}\mathrm{TS} \\
\text { result } \\
(\mathrm{mg} / \mathrm{L})\end{array}$ & Response function & $R^{2}$ \\
\hline \multicolumn{7}{|c|}{$\begin{array}{l}\text { Non-pressure } \\
1 \mathrm{~atm}\end{array}$} \\
\hline $\begin{array}{c}\text { Maleic } \\
\text { acid }\end{array}$ & 3.53 & 32.48 & 9.97 & 83.45 & $\begin{aligned}= & +64.88+10.60 \times \mathrm{A}+7.94 \times \mathrm{B}+7.36 \times \mathrm{C}+8.40 \times \mathrm{A} \times \mathrm{B}-3.09 \times \mathrm{A} \times \mathrm{C}+2.37 \times \mathrm{B} \times \mathrm{C}-10.22 \times \mathrm{A}^{2}-21.12 \times \mathrm{B}^{2}+ \\
& 8.28 \times \mathrm{C}^{2}\end{aligned}$ & 0.93 \\
\hline $\begin{array}{l}\text { Fumaric } \\
\text { acid }\end{array}$ & 3.87 & 31.54 & 8.28 & 92.59 & $\begin{aligned}= & +86.82+4.74 \times \mathrm{A}+4.30 \times \mathrm{B}+16.84 \times \mathrm{C}+0.37 \times \mathrm{A} \times \mathrm{B}+1.62 \times \mathrm{A} \times \mathrm{C}+4.56 \times \mathrm{B} \times \mathrm{C}-7.42 \times \mathrm{A}^{2}-17.42 \times \mathrm{B}^{2}-17 .\end{aligned}$ & 0.94 \\
\hline $\begin{array}{r}\text { Oxalic } \\
\text { acid }\end{array}$ & 2.37 & 30.58 & 8.41 & 79.58 & $+76.18-0.26 \times \mathrm{A}+4.96 \times \mathrm{B}+10.74 \times \mathrm{C}-0.88 \times \mathrm{A} \times \mathrm{B}-2.13 \times \mathrm{A} \times \mathrm{C}-0.66 \times \mathrm{B} \times \mathrm{C}-2.50 \times \mathrm{A}^{2}-13.82 \times \mathrm{B}^{2}-10.37 \times \mathrm{C}^{2}$ & 0.96 \\
\hline $\begin{array}{r}\text { Acetic } \\
\text { acid }\end{array}$ & 4.83 & 27.64 & 5.93 & 317.319 & $\begin{aligned}= & +287.35+47.68 \times \mathrm{A}+22.72 \times \mathrm{B}+25.11 \times \mathrm{C}+12.35 \times \mathrm{A} \times \mathrm{B}-35.22 \times \mathrm{A} \times \mathrm{C}+4.12 \times \mathrm{B} \times \mathrm{C}-16.58 \times \mathrm{A}^{2}-138.12 \times \\
& \mathrm{B}^{2}-44.23 \times \mathrm{C}^{2}\end{aligned}$ & 0.95 \\
\hline \multicolumn{7}{|l|}{$\begin{array}{l}\text { Pressure } \\
1.2 \mathrm{~atm}\end{array}$} \\
\hline $\begin{array}{c}\text { Maleic } \\
\text { acid }\end{array}$ & 3.22 & 30.50 & 8.70 & 97.26 & $\begin{aligned}= & +92.41+1.80 \times \mathrm{A}+8.90 \mathrm{xB}+14.15 \times \mathrm{C}-0.74 \times \mathrm{A} \times \mathrm{B}+4.19 \times \mathrm{A} \times \mathrm{C}-2.35 \times \mathrm{B} \times \mathrm{C}-14.70 \times \mathrm{A}^{2}-21.39 \times \mathrm{B}^{2}-1 \\
& 2.64 \times \mathrm{C}^{2}\end{aligned}$ & 0.91 \\
\hline $\begin{array}{c}\text { Fumaric } \\
\text { acid }\end{array}$ & 4.13 & 30.96 & 8.60 & 91.37 & $\begin{aligned}= & +84.53+5.29 \times \mathrm{A}+7.17 \times \mathrm{B}+15.48 \times \mathrm{C}+0.29 \times \mathrm{A} \times \mathrm{B}+4.56 \times \mathrm{A} \times \mathrm{C}+2.43 \times \mathrm{B} \times \mathrm{C}-7.15 \times \mathrm{A}^{2}-22.23 \times \mathrm{B}^{2}-15.46 \\
& \times \mathrm{C}^{2}\end{aligned}$ & 0.93 \\
\hline $\begin{array}{r}\text { Oxalic } \\
\text { acid }\end{array}$ & 3.15 & 31.61 & 8.85 & 97.85 & $\begin{aligned}= & +92.35+3.46 \times \mathrm{A}+132.57 \times \mathrm{B}-113.01 \times \mathrm{C}+2.24 \times \mathrm{A} \times \mathrm{B}+3.75 \times \mathrm{A} \times \mathrm{C}-122.13 \times \mathrm{B} \times \mathrm{C}-73.36 \times \mathrm{A}^{2}+42.08 \times \mathrm{B}^{2}+46.67 \times \mathrm{C}^{2}- \\
& 125.11 \times \mathrm{A}^{2} \times \mathrm{B}+134.56 \times \mathrm{A}^{2} \mathrm{xC}+1.07 \times \mathrm{A} \times \mathrm{B}^{2}\end{aligned}$ & 0.92 \\
\hline $\begin{array}{r}\text { Acetic } \\
\text { acid }\end{array}$ & 3.93 & 32.41 & 6.50 & 409.16 & $\begin{aligned}= & +347.18+51.76 \times \mathrm{A}+37.04 \times \mathrm{B}+22.19 \times \mathrm{C}-28.31 \times \mathrm{A} \times \mathrm{B}-44.49 \times \mathrm{A} \times \mathrm{C}-12.32 \times \mathrm{B} \times \mathrm{C}+14.19 \times \mathrm{A}^{2}-122.9 \\
& 1 \times \mathrm{B}^{2}-80.85 \times \mathrm{C}^{2}\end{aligned}$ & 0.91 \\
\hline
\end{tabular}

highest value of sugar concentration of $6 \mathrm{mg} / \mathrm{L}$ at $120^{\circ} \mathrm{C}$ and $1 \mathrm{~atm}$ pressure with $1 \mathrm{~h}$ reaction time [36].

Highest RS formation results were predicted via mathematical models, which were derived by Box-Behnken statistical design experiments, for all different organic acids. Mathematical models, $\mathrm{R}^{2}$ values, and optimum points of all 3 different factors are given in Table 7 for highest RS concentration with 4 different organic acid pretreatments. It is obviously said that pretreatment with acetic acid was more significantly affected RS formation than the other organic acids. RS concentration can be rise over $409 \mathrm{mg} / \mathrm{L}$ under pressure conditions with acetic acid application. While pressure changing cannot be affected significantly the RS formation with fumaric acid pretreatment, RS result was increase averagely $15 \%$ with maleic acid and oxalic acid pretreatment when the pressure was applied.

\section{Economic evaluation}

Economic evaluation for TS production with different organic acids and both with and without pressure conditions were calculated. The cost of organic acids is different for each, which is why biomass pretreatment cost could vary according to treated organic acids. Organic acids prices are collected from bulk producers of chemical market, where the chemicals purity is over $95 \%$. Before collecting market prices of acids, literature prices were checked and verified
Table 8 Economical evaluation of pretreatments of different organic acid under pressure and non-pressure conditions

\begin{tabular}{lllclc}
\hline Pretreatment & Acid ratio (\%) & Time (Min.) & $\begin{array}{l}\text { TS result } \\
(\mathrm{mg} / \mathrm{L})\end{array}$ & $\begin{array}{l}\text { Chemical Unit } \\
\text { Cost }(\$ / \mathrm{kg})\end{array}$ & $\begin{array}{l}\text { Cost for Unit } \\
\text { TS }(\$ / \mathrm{gTS} . \mathrm{h})\end{array}$ \\
\hline $\begin{array}{l}\text { Non-pressure } \\
1 \text { atm }\end{array}$ & & & & \\
$\quad$ Maleic acid & 4.99 & 31.47 & 7452.81 & 2.85 & 19.08 \\
Fumaric acid & 4.03 & 30.92 & 7599.38 & 1.33 & 7.05 \\
Oxalic acid & 3.29 & 29.97 & 8147.5 & 0.73 & 2.95 \\
Acetic acid & 4.92 & 29.09 & $15,643.9$ & 0.55 & 1.73 \\
Pressure & & & & & \\
1.2 atm & & & 8895.9 & 2.85 & 10.38 \\
Maleic acid & 3.24 & 28.49 & 8166.26 & 1.33 & 6.29 \\
Fumaric acid & 3.86 & 30.83 & 8818.01 & 0.73 & 2.85 \\
Oxalic acid & 3.44 & 33.74 & $17,507.8$ & 0.55 & 1.51 \\
Acetic acid & 4.82 & 30.47 & & & \\
\hline
\end{tabular}


with market prices to avoid price fluctuations caused by Covid-19 and economical unbalanced market situations [37-41]. First, average unit prices for each acid were determined, then used for equation (Eq. 1).

Economical evaluation results given in Table 8 are for pretreatment of all different acids. It is clear that the acetic acid has promising chemical because of lower unit price than others and easy production. $1.5 \$ / \mathrm{gTS}$ is the minimum cost for the TS formation with acetic acid pretreatment. There are two reason for this 1.5 price, one acetic acid gave higher TS results and unit price of acetic acid considerably lower than the other organic acids. Although oxalic acid price almost similar the acetic acid price, unit cost of almost doubled when compare the acetic acid. Because TS formation yield with oxalic acid are nearly $50 \%$ for TS formation of acetic acid pretreatment. When compare with acetic acid and oxalic acid, it is certain that maleic acid and fumaric acid are not economically available.

\section{Conclusion}

In this study pretreatment experiments have been made with maleic acid, fumaric acid, oxalic acid, and acetic acid. These experiments were carried out both under pressure conditions and under non-pressure conditions. To make the experiments more economical, reliable, and acceptable, Box-Behnken experimental design method was preferred and time, acid ratio, and solid ratio were chosen as factors with center points. In general, the results obtained from the experiments show that organic acids are very effective in pretreatment. It's known that organic acids like citric and acetic acid, which are commonly used at pharmaceutical and food industry, efficient alternatives for pretreatment instead of strong acids. Plus these kind of organic acids could be additional organic nutrient sources at the fermentation medium, which is required for bioenergy production with treated biomass material [36]. Pretreatment of acetic acid result was giving the highest concentration of $409.16 \mathrm{~g} / \mathrm{L}$ total sugar. The maximum TS concentration of maleic, oxalic, and fumaric acid were $97.26,97.85$, and $91.37 \mathrm{~g} / \mathrm{L}$, respectively, and these results were observed under pressure of $1.2 \mathrm{~atm}$ conditions. The results of the economic analysis show pretreatment cost of acetic acid pretreatment was found averagely $1.51 \$ /$ gTS under $1.2 \mathrm{~atm}$ pressure conditions. It is clearly seen that organic acids are more advantageous than mineral acids when the mineral acids used in the present applications release compounds such as furfural, which will inhibit fermentation during the breakdown of cellulose and hemicellulose, and its high rate of corrosion. When the result derived from experiments, it is clear that under pressure conditions are almost better than the non-pressure conditions. This research has some limitation, especially higher-pressure conditions should be studies at later studies and sugar form may be determined in addition to the total sugar and reduced sugar concentration. The studies of biological production and bioenergy component production can be studied to understand biomass availability.

Supplementary Information The online version contains supplementary material available at https://doi.org/10.1007/s10163-021-01276-7.

Acknowledgements This study was derived by the Master of Science thesis of "Optimization of Pretreatment Factors with Organic Acids under Pressure-Dependent Conditions of Sugar Beet Pulp" from Niğde Ömer Halisdemir University

\section{References}

1. Fanchi JR, Fanchi CJ (2017) Energy in the 21st century. World Scientific Publishing Company

2. Saha BCBC (2003) Hemicellulose bioconversion. J Ind Microbiol Biotechnol 30:279-291. https://doi.org/10.1007/ s10295-003-0049-x

3. Tedesco S, Marrero Barroso T, Olabi AG (2014) Optimization of mechanical pre-treatment of Laminariaceae spp. biomass-derived biogas. Renew Energy 62:527-534. https://doi.org/10.1016/j. renene.2013.08.023

4. Adigüzel AO (2020) Production and characterization of thermo-, halo- and solvent-stable esterase from Bacillus mojavensis TH309. Biocatal Biotransformation. https://doi.org/10.1080/10242422. 2020.1715370

5. Asakawa AA, Kohara M, Sasaki C, Asada C, Nakamura Y (2015) Comparison of choline acetate ionic liquid pretreatment with various pretreatments for enhancing the enzymatic saccharification of sugarcane bagasse. Ind Crops Prod 71:147-152. https://doi.org/ 10.1016/j.indcrop.2015.03.073

6. Luste S, Luostarinen S (2011) Enhanced methane production from ultrasound pre-treated and hygienized dairy cattle slurry. Waste Manag 31:2174-2179. https://doi.org/10.1016/j.wasman.2011.04. 012

7. Michalsk K, Ledakowicz S (2014) Alkaline hydrogen peroxide pretreatment of energy crops for biogas production. Chem Pap 68:913-922. https://doi.org/10.2478/s11696-013-0531-5

8. Mosier N, Wyman C, Dale B, Elander R, Lee YY, Holtzapple M, Ladisch M (2005) Features of promising technologies for pretreatment of lignocellulosic biomass. Bioresour Technol 96:673-686. https://doi.org/10.1016/j.biortech.2004.06.025

9. Lloyd TA, Wyman CE (2005) Combined sugar yields for dilute sulfuric acid pretreatment of corn stover followed by enzymatic hydrolysis of the remaining solids. Bioresour Technol 96:19671977. https://doi.org/10.1016/j.biortech.2005.01.011

10. Zhu Z, Sathitsuksanoh N, Vinzant T, Schell DJ, McMillan JD, Zhang Y-HP (2009) Comparative study of corn stover pretreated by dilute acid and cellulose solvent-based lignocellulose fractionation: Enzymatic hydrolysis, supramolecular structure, and substrate accessibility. Biotechnol Bioeng 103:715-724. https:// doi.org/10.1002/bit.22307

11. Palmqvist E, Hahn-Hägerdal B (2000) Fermentation of lignocellulosic hydrolysates. II: Inhibitors and mechanisms of inhibition. 
Bioresour Technol 74:25-33. https://doi.org/10.1016/S09608524(99)00161-3

12. Cantarella M, Cantarella L, Alberto Gallifuoco AS, Alfani F (2004) Effect of inhibitors released during steam-explosion treatment of poplar wood on subsequent enzymatic hydrolysis and SSF. Biotechnol Prog 20:200-206. https://doi.org/10.1021/bp025 7978

13. Klinke HB, Thomsen AB, Ahring BK (2004) Inhibition of ethanol-producing yeast and bacteria by degradation products produced during pre-treatment of biomass. Appl Microbiol Biotechnol 66:10-26. https://doi.org/10.1007/s00253-004-1642-2

14. Kootstra AMJ, Beeftink HH, Scott EL, Sanders JPM (2009) Comparison of dilute mineral and organic acid pretreatment for enzymatic hydrolysis of wheat straw. Biochem Eng J 46:126-131. https://doi.org/10.1016/j.bej.2009.04.020

15. Kootstra AMJ, Beeftink HH, Scott EL, Sanders JPM (2009) Optimization of the dilute maleic acid pretreatment of wheat straw. Biotechnol Biofuels. https://doi.org/10.1186/1754-6834-2-31

16. Zhang T, Kumar R, Wyman CE (2013) Sugar yields from dilute oxalic acid pretreatment of maple wood compared to those with other dilute acids and hot water. Carbohydr Polym 92:334-344. https://doi.org/10.1016/j.carbpol.2012.09.070

17. Kim Y, Kreke T, Ladisch MR (2013) Reaction mechanisms and kinetics of xylo-oligosaccharide hydrolysis by dicarboxylic acids. AIChE J 59:188-199. https://doi.org/10.1002/aic.13807

18. Lim W-S, Lee J-W (2013) Effects of pretreatment factors on fermentable sugar production and enzymatic hydrolysis of mixed hardwood. Bioresour Technol 130:97-101. https://doi.org/10. 1016/j.biortech.2012.11.122

19. Lu Y, Mosier NS (2007) Biomimetic catalysis for hemicellulose hydrolysis in corn stover. Biotechnol Prog 23:116-123. https:// doi.org/10.1021/bp060223e

20. Qin L, Liu ZH, Li BZ, Dale BE, Yuan YJ (2012) Mass balance and transformation of corn stover by pretreatment with different dilute organic acids. Bioresour Technol 112:319-326. https://doi. org/10.1016/j.biortech.2012.02.134

21. Seta FT, An X, Liu L, Zhang H, Yang J, Zhang W, Nie S, Yao S, Cao H, Xu Q, Bu Y, Liu H (2020) Preparation and characterization of high yield cellulose nanocrystals (CNC) derived from ball mill pretreatment and maleic acid hydrolysis. Carbohydr Polym 234:115942. https://doi.org/10.1016/j.carbpol.2020.115942

22. Yu H, Xiao W, Han L, Huang G (2019) Characterization of mechanical pulverization/phosphoric acid pretreatment of corn stover for enzymatic hydrolysis. Bioresour Technol 282:69-74. https://doi.org/10.1016/j.biortech.2019.02.104

23. Arumugam A, Malolan VV, Ponnusami V (2020) Contemporary pretreatment strategies for bioethanol production from corncobs: a comprehensive review. Springer, Netherlands

24. Qing Q, Huang M, He Y, Wang L, Zhang Y (2015) Dilute oxalic acid pretreatment for high total sugar recovery in pretreatment and subsequent enzymatic hydrolysis. Appl Biochem Biotechnol 177:1493-1507. https://doi.org/10.1007/s12010-015-1829-2

25. Greetham D, Adams JM, Du C (2020) The utilization of seawater for the hydrolysis of macroalgae and subsequent bioethanol fermentation. Sci Rep. https://doi.org/10.1038/s41598-020-66610-9

26. DuBois M, Gilles KA, Hamilton JK, Rebers PA, Smith F (1956) Colorimetric method for determination of sugars and related substances. Anal Chem 28(3):350-356. https://doi.org/10.1021/ac601 $11 \mathrm{a} 017$

27. Miller GL (1959) Use of dinitrosalicylic acid reagent for determination of reducing sugar. Anal Chem 31(3):426-428. https://doi. org/10.1021/ac60147a030
28. Sahu S, Pramanik K (2018) Evaluation and optimization of organic acid pretreatment of cotton gin waste for enzymatic hydrolysis and bioethanol production. Appl Biochem Biotechnol 186:1047-1060. https://doi.org/10.1007/s12010-018-2790-7

29. Bukhari NA, Jahim JM, Loh SK, Nasrin AB, Harun S, Abdul PM (2020) Organic acid pretreatment of oil palm trunk biomass for succinic acid production. Waste Biomass Valoriz. https://doi.org/ 10.1007/s12649-020-00953-2

30. Rattanaporn K, Tantayotai P, Phusantisampan T, Pornwongthong P, Sriariyanun M (2018) Organic acid pretreatment of oil palm trunk: effect on enzymatic saccharification and ethanol production. Bioprocess Biosyst Eng 41:467-477. https://doi.org/10.1007/ s00449-017-1881-0

31. Oktaviani M, Hermiati E, Thontowi A, Laksana RPB, Kholida LN, Andriani A, Mangunwardoyo W (2019) Production of xylose, glucose, and other products from tropical lignocellulose biomass by using maleic acid pretreatment. IOP Conf Ser Earth Environ Sci. https://doi.org/10.1088/1755-1315/251/1/012013

32. Barisik G, Isci A, Kutlu N, Bagder Elmaci S, Akay B (2016) Optimization of organic acid pretreatment of wheat straw. Biotechnol Prog 32:1487-1493. https://doi.org/10.1002/btpr.2347

33. Amnuaycheewa P, Hengaroonprasan R, Rattanaporn K, Kirdponpattara S, Cheenkachorn K, Sriariyanun M (2016) Enhancing enzymatic hydrolysis and biogas production from rice straw by pretreatment with organic acids. Ind Crops Prod 87:247-254. https://doi.org/10.1016/j.indcrop.2016.04.069

34. Silva TAL, Zamora HDZ, Varão LHR, Prado NS, Baffi MA, Pasquini D (2018) Effect of steam explosion pretreatment catalysed by organic acid and alkali on chemical and structural properties and enzymatic hydrolysis of sugarcane bagasse. Waste Biomass Valoriz 9:2191-2201. https://doi.org/10.1007/s12649-017-9989-7

35. Gong G, Liu D, Huang Y (2010) Microwave-assisted organic acid pretreatment for enzymatic hydrolysis of rice straw. Biosyst Eng 107:67-73. https://doi.org/10.1016/j.biosystemseng.2010.05.012

36. Vanegas $\mathrm{CH}$, Hernon A, Bartlett J (2015) Enzymatic and organic acid pretreatment of seaweed: effect on reducing sugars production and on biogas inhibition. Int J Ambient Energy 36:2-7. https://doi.org/10.1080/01430750.2013.820143

37. De Carvalho JC, Magalhães AI, Soccol CR (2018) Biobased itaconic acid market and research trends-is it really a promising chemical? Chim Oggi Chem Today 36:56-58

38. Mangili PV, Junqueira PG, Santos LS, Prata DM (2019) Ecoefficiency and techno-economic analysis for maleic anhydride manufacturing processes. Clean Technol Environ Policy. https:// doi.org/10.1007/s10098-019-01693-1

39. Martin-Dominguez V, Estevez J, De Borja Ojembarrena F, Santos VE, Ladero M (2018) Fumaric acid production: a biorefinery perspective. Fermentation 4(2):33

40. Han L, Xie S, Liu S, Sun J, Jia Y, Jing Y (2017) Effects of sodium chloride on the thermal behavior of oxalic acid dihydrate for thermal energy storage. Appl Energy. https://doi.org/10.1016/j.apene rgy.2016.10.104

41. Prakoso T, Hanley J, Soebianta MN, Soerawidjaja TH, Indarto A (2018) Synthesis of terpineol from $\alpha$-pinene using low-price acid catalyst. Catal Letters. https://doi.org/10.1007/s10562-017-2267-2

Publisher's Note Springer Nature remains neutral with regard to jurisdictional claims in published maps and institutional affiliations. 